\title{
Left Ventricular Dysfunction Assessed by Cardiac Time Interval Analysis Among Different Geometric Patterns in Untreated Hypertension
}

\author{
Kunitsugu Takasaki, MD; Masaaki Miyata, MD; Masakazu Imamura, MD; Toshinori Yuasa, MD; \\ Eiji Kuwahara, MD; Kayoko Kubota, MD; Mihoko Kono, MD; Nami Ueya, MD; \\ Yoshihisa Horizoe, MD; Hideto Chaen, MD; Naoko Mizukami, PhD; \\ Akira Kisanuki, MD; Shuichi Hamasaki, MD; Chuwa Tei, MD
}

\begin{abstract}
Background: Left ventricular (LV) hypertrophy is a powerful independent predictor of morbidity and mortality in hypertensive patients. Abnormal LV geometric patterns are also associated with hypertensive complications, and concentric hypertrophy is associated with the highest mortality in hypertensive patients. However, the relationship between geometric patterns and cardiac dysfunction is not fully established. We hypothesized that the Tei index, which is a measure of global cardiac function, is a feasible parameter for estimating cardiac dysfunction among the different LV geometric patterns in hypertensive patients.
\end{abstract}

Methods and Results: We enrolled 60 consecutive patients with untreated essential hypertension. Subjects were divided into 4 groups: normal geometry, concentric remodeling, eccentric hypertrophy and concentric hypertrophy. We measured ejection fraction, mitral E/A ratio, Tei index, ejection time, and isovolumic contraction and relaxation times. There were significant correlations between LV mass index and systolic blood pressure $(P<0.01)$, ejection fraction $(P<0.05)$, mitral $E / A$ ratio $(P<0.05)$ and Tei index $(P<0.0001)$. In multiple regression analysis, only the Tei index independently correlated with LV mass index $(P<0.01)$. Concentric hypertrophy significantly increased the Tei index compared with the other 3 groups.

Conclusions: The Tei index provides a better marker for LV dysfunction by hypertensive hypertrophy than conventional parameters. LV function in concentric hypertrophy was most impaired among all the geometric patterns in untreated hypertensive patients. (Circ J 2012; 76: 1409-1414)

Key Words: Echocardiography; Hypertension; Left ventricular function; Left ventricular hypertrophy

$\mathbf{E}$ ssential hypertension is a major risk factor for cardiovascular disease. In hypertensive patients, pressure and/or volume overload leads to left ventricular (LV) hypertrophy, which is a powerful independent predictor of morbidity and mortality. ${ }^{1}$ Hypertensive LV hypertrophy causes heart failure, especially diastolic heart failure, which is heart failure with a normal LV ejection fraction (LVEF) because of LV diastolic dysfunction. However, several studies have reported that patients with diastolic heart failure have not only diastolic dysfunction but also systolic dysfunction, when parameters other than LVEF were used to evaluate systolic function. $^{2-5}$ Therefore, global cardiac function including systolic and diastolic LV function should be evaluated by non-conventional functional parameters such as the Tei index. The Tei index, combining systolic and diastolic functional parameters, may be a better and simpler parameter to estimate LV global function than conventional indices of purely systolic or diastolic function in hypertensive patients.

Based on LV mass and relative wall thickness, patients with essential hypertension can be classified into 4 different LV geometric patterns: normal, concentric remodeling, concentric hypertrophy and eccentric hypertrophy. ${ }^{6-8}$ Previous studies have reported that abnormal LV geometric patterns are associated with a greater risk of hypertensive complications, and patients with concentric LV hypertrophy have the highest mortality and cardiovascular event rate. ${ }^{7,9}$ The relation between these 4 different LV geometric patterns and LV function has not been elucidated. Therefore, we aimed to investigate the correlation

Received November 28, 2011; revised manuscript received January 29, 2012; accepted January 30, 2012; released online March 17, 2012 Time for primary review: 21 days

Department of Cardiovascular, Respiratory and Metabolic Medicine, Graduate School of Medicine, Kagoshima University, Kagoshima, Japan

Mailing address: Masaaki Miyata, MD, FAHA, FACC, Department of Cardiovascular, Respiratory and Metabolic Medicine, Graduate School of Medicine, Kagoshima University, 8-35-1 Sakuragaoka, Kagoshima 890-8520, Japan. E-mail: miyatam@m3.kufm.kagoshimau.ac.jp

ISSN-1346-9843 doi:10.1253/circj.CJ-11-1369

All rights are reserved to the Japanese Circulation Society. For permissions, please e-mail: cj@j-circ.or.jp 


\begin{tabular}{|c|c|}
\hline Age (years) & $50 \pm 14$ \\
\hline Gender (M/F) & $30 / 30$ \\
\hline BMI $\left(\mathrm{kg} / \mathrm{m}^{2}\right)$ & $25 \pm 4$ \\
\hline Body surface area $\left(\mathrm{m}^{2}\right)$ & $1.65 \pm 0.19$ \\
\hline Heart rate (beats/min) & $68 \pm 11$ \\
\hline Systolic BP (mmHg) & $164 \pm 19$ \\
\hline Diastolic BP (mmHg) & $98 \pm 16$ \\
\hline Stage 1 hypertension (\%) & 32 \\
\hline Stage 2 hypertension (\%) & 33 \\
\hline Stage 3 hypertension (\%) & 35 \\
\hline Dyslipidemia (n, \%) & $18(30 \%)$ \\
\hline Total cholesterol (mg/dl) & $203 \pm 33$ \\
\hline Triglycerides (mg/dl) & $112 \pm 56$ \\
\hline HDL-cholesterol (mg/dl) & $62 \pm 22$ \\
\hline Diabetes mellitus (n, \%) & $18(30 \%)$ \\
\hline Fasting plasma glucose (mg/dl) & $106 \pm 25$ \\
\hline $\mathrm{HbA}_{1 \mathrm{c}}(\%)$ & $5.2 \pm 1.2$ \\
\hline Creatinine $(\mathrm{mg} / \mathrm{dl})$ & $0.7 \pm 0.2$ \\
\hline
\end{tabular}

Values are mean $\pm \mathrm{SD}$.

BMI, body mass index; BP, blood pressure.

\begin{tabular}{|lc|}
\hline \multicolumn{2}{|l|}{ Table 2. Echocardiographic Measurements $(\mathbf{n = 6 0})$} \\
LV diastolic dimension $(\mathrm{mm})$ & $49 \pm 5$ \\
Interventricular septum thickness $(\mathrm{mm})$ & $11 \pm 3$ \\
LV posterior wall thickness $(\mathrm{mm})$ & $10 \pm 2$ \\
Relative wall thickness & $0.40 \pm 0.10$ \\
LV mass $(\mathrm{g})$ & $182 \pm 61$ \\
LV mass index $\left(\mathrm{g} / \mathrm{m}^{2}\right)$ & $110 \pm 35$ \\
LVEF $(\%)$ & $69 \pm 9$ \\
Mitral E/A ratio & $1.0 \pm 0.3$ \\
Mitral E deceleration time $(\mathrm{ms})$ & $207 \pm 52$ \\
LV Tei index & $0.44 \pm 0.13$ \\
ICT (ms) & $33 \pm 20$ \\
IRT (ms) & $95 \pm 24$ \\
ET (ms) & $296 \pm 28$ \\
\hline
\end{tabular}

Values are mean $\pm S D$.

LV, left ventricular; LVEF, left ventricular ejection fraction; ICT, isovolumic contraction time; IRT, isovolumic relaxation time; $\mathrm{ET}$, ejection time.

between LV mass and LV function and the effect of LV geometry on the severity of LV dysfunction in patients with untreated essential hypertension.

\section{Methods}

\section{Subjtects}

We enrolled 60 consecutive patients with untreated essential hypertension and without heart failure symptoms (mean age, $50 \pm 14 ; 50 \%$ male). Blood pressure (BP) was measured at the office with a calibrated mercury sphygmomanometer after a 5-min rest while seated on 2 different occasions. Hypertension was defined as systolic BP $\geq 140 \mathrm{mmHg}$ or diastolic BP $\geq 90 \mathrm{mmHg}$. Stage 1 hypertension was defined as systolic BP of $140-159 \mathrm{mmHg}$ or diastolic BP of $90-99 \mathrm{mmHg}$, stage 2 hypertension was defined as systolic BP of $160-179 \mathrm{mmHg}$ or diastolic BP of 100-109 $\mathrm{mmHg}$, and stage 3 hypertension was defined as systolic $\mathrm{BP} \geq 180 \mathrm{mmHg}$, diastolic $\mathrm{BP} \geq 110 \mathrm{mmHg} .{ }^{10}$

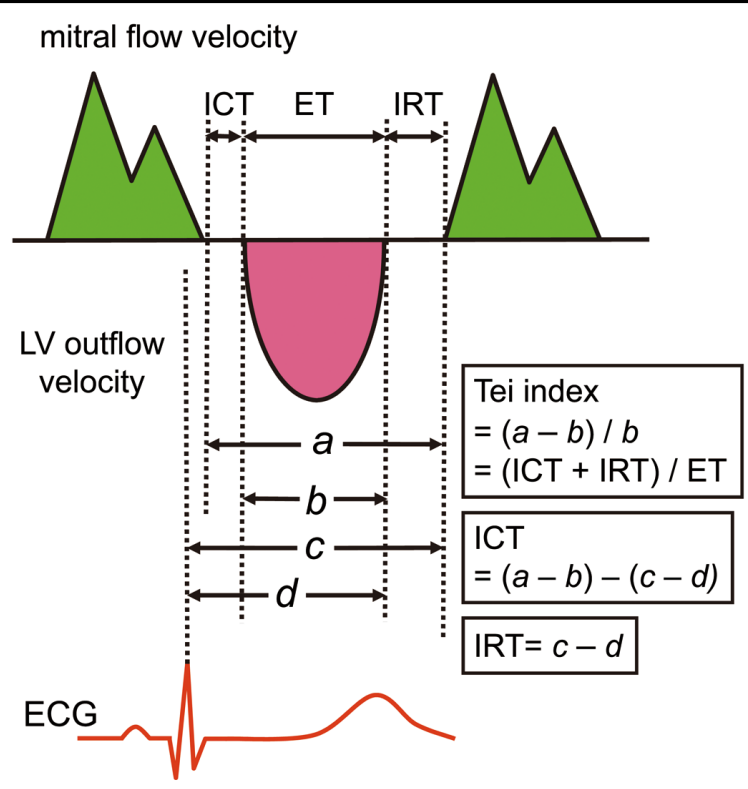

Figure 1. Measurement of the Tei index with Doppler echocardiography. ECG, electrocardiogram; ET, ejection time; ICT, isovolumic contraction time; IRT, isovolumic relaxation time; LV, left ventricular; "a", the time interval from the cessation to the onset of mitral inflow; " $b$ ", the time interval from the onset to the cessation of aortic flow; " $c$ ", the time interval between the peak of the QRS complex in the ECG and the onset of mitral inflow; " $d$ ", the time interval between the peak of the QRS and the cessation of LV ejection flow.

Patients were excluded if they had secondary hypertension, ischemic heart disease, atrial fibrillation, congenital heart disease, or other organic heart disease such as significant valvular disease. The patients' characteristics are summarized in Table 1. This protocol was approved by the Institutional Committee of Kagoshima University Hospital, and written informed consent was given by all patients.

\section{Echocardiography and Cardiac Time Interval Analysis}

Standard 2-dimensional and Doppler echocardiography were performed using a commercially available echocardiographic machine (ATL HDI 5000) with a 2.0-3.5-MHz transducer. Interventricular septal thickness (IVS), posterior wall thickness (PWT) and LV internal dimension (LVID) were measured at end-diastole according to established standards of the American Society of Echocardiography (ASE). ${ }^{11}$ LVEF was obtained using a modified biplane Simpson's method from the apical 2- and 4-chamber views. LV mass was calculated according to the ASE-recommended formula: ${ }^{11}$

$$
\begin{aligned}
\mathrm{LV} \text { mass }(\mathrm{g})= & 0.8 \times\left\{1.04\left[(\mathrm{IVS}+\mathrm{LVID}+\mathrm{PWT})^{3}-(\mathrm{LVID})^{3}\right]\right\} \\
& +0.6
\end{aligned}
$$

LV mass was divided by body surface area to obtain the LV mass index (LVMI). Relative wall thickness (RWT) was also calculated using the formula:

$$
\text { RWT }=(2 \times \text { PWT }) / L V I D
$$

The LV geometry in each subject was classified into 1 of 4 patterns based on LVMI and RWT: (1) normal when LVMI was $\leq 115 \mathrm{~g} / \mathrm{m}^{2}$ for men and $\leq 95 \mathrm{~g} / \mathrm{m}^{2}$ for women, and RWT was $\leq 0.42$; (2) concentric remodeling when LVMI was $\leq 115 \mathrm{~g} / \mathrm{m}^{2}$ for men and $\leq 95 \mathrm{~g} / \mathrm{m}^{2}$ for women, and RWT was $>0.42$; (3) 


\begin{tabular}{|c|c|c|c|c|}
\hline & \multicolumn{2}{|c|}{ Single regression analysis } & \multicolumn{2}{|c|}{ Multiple regression analysis } \\
\hline & r value & $\begin{array}{c}\text { Univariate } P \\
\text { value }\end{array}$ & $\begin{array}{c}\text { Multivariate } P \\
\text { value }\end{array}$ & Coefficient \\
\hline Age (years) & 0.10 & NS & NA & NA \\
\hline $\mathrm{BMI}\left(\mathrm{kg} / \mathrm{m}^{2}\right)$ & 0.03 & NS & NA & NA \\
\hline Systolic BP (mm Hg) & 0.34 & $<0.01$ & NS & 0.181 \\
\hline Diastolic BP (mmHg) & 0.16 & NS & NA & NA \\
\hline LVEF (\%) & -0.33 & $<0.05$ & NS & -0.131 \\
\hline Mitral E/A ratio & -0.30 & $<0.05$ & NS & -0.101 \\
\hline Mitral E deceleration time (ms) & 0.22 & NS & NA & NA \\
\hline LV Tei index & 0.50 & $<0.0001$ & $<0.05$ & 0.346 \\
\hline
\end{tabular}

NS, not significant; NA, not available. Other abbreviations see in Tables 1,2.
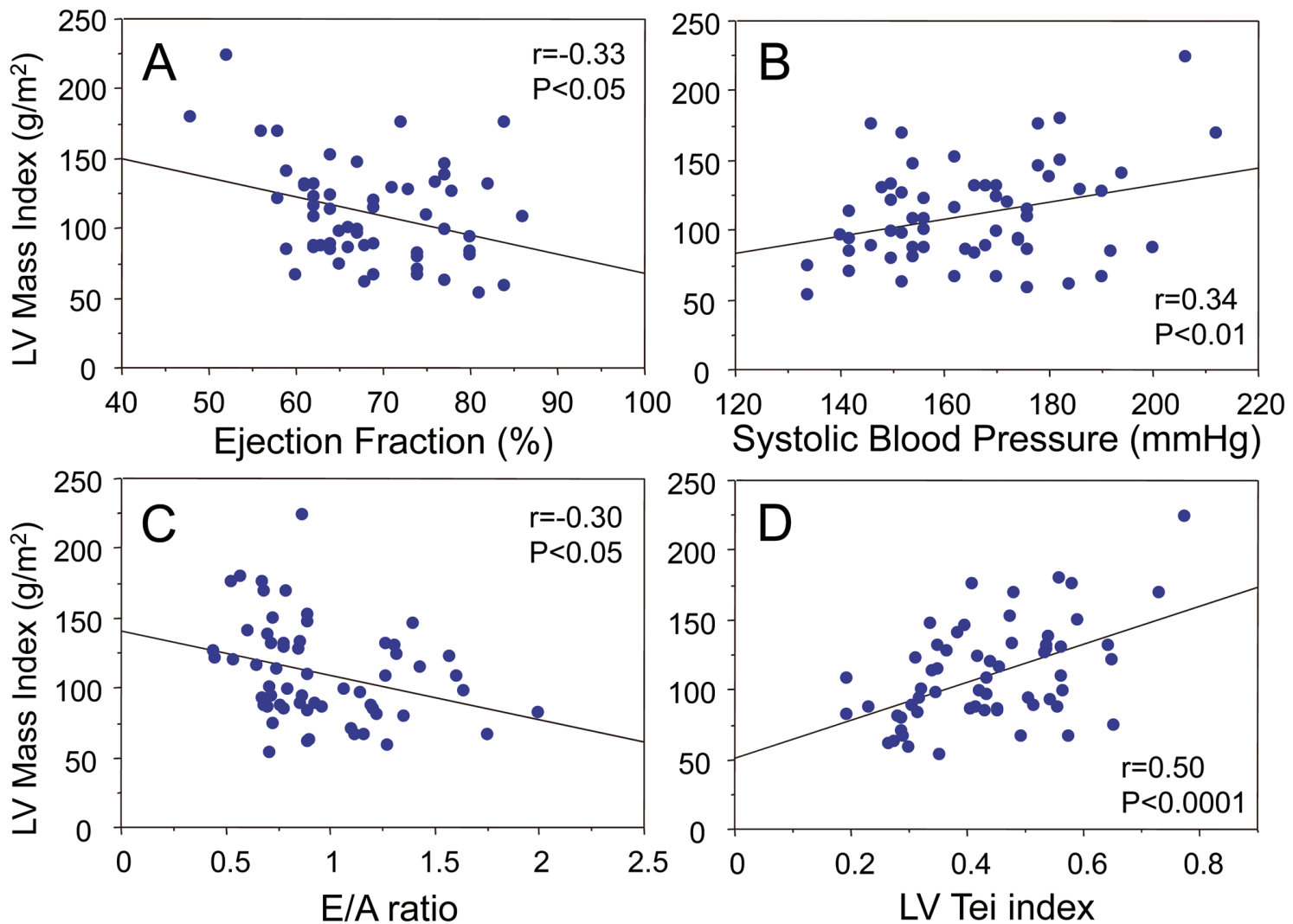

Figure 2. Associations between left ventricular (LV) mass index and blood pressure or the cardiac functional parameters.

concentric hypertrophy when LVMI was $>115 \mathrm{~g} / \mathrm{m}^{2}$ for men and $>95 \mathrm{~g} / \mathrm{m}^{2}$ for women, and RWT was $>0.42$; and (4) eccentric hypertrophy when LVMI was $>115 \mathrm{~g} / \mathrm{m}^{2}$ for men and $>95 \mathrm{~g} / \mathrm{m}^{2}$ for women, and RWT was $<0.42 .6,7$

Pulsed Doppler recordings of mitral flow velocities were obtained from the apical 4-chamber view by placing the sample volume between the tips of the mitral leaflets, and LV outflow velocities were obtained by placing the sample volume in the outflow tract below the aortic valve leaflets. Peak early (E) and late diastolic (A) transmitral filling flow velocities, E/A ratio and deceleration time (DcT) of the $\mathrm{E}$ wave were measured.

Doppler time intervals were also measured from the mitral inflow and LV outflow velocities. The interval " $a$ " was taken from the cessation to the onset of mitral inflow and this was equal to the sum of isovolumic contraction time (ICT), ejection time (ET) and isovolumic relaxation time (IRT) (Figure 1). The interval " $b$ " was taken from the onset to the cessation of aortic flow and this was the LV ET. Thus, the sum of ICT and IRT was obtained by subtracting interval " $b$ " from " $a$ ". The Tei index, combining systolic and diastolic function, was defined as the sum of ICT and IRT divided by ET: $(a-b) / b$. We also measured the interval " $c$ " between the peak of the QRS complex and the onset of mitral inflow, and the interval " $d$ " between the peak of the QRS complex and the cessation of LV outflow. Therefore, IRT $=c-d$, and ICT $=(a-b)-(c-d)$. Data 
Table 4. Correlations Between LV Mass Index and Cardiac Time Intervals

\begin{tabular}{lcccc} 
& r value & $\begin{array}{c}\text { Univariate } \mathbf{P} \\
\text { value }\end{array}$ & $\begin{array}{c}\text { Multivariate } \mathbf{P} \\
\text { value }\end{array}$ & $\begin{array}{c}\text { Standardized } \\
\text { regression coefficient }\end{array}$ \\
$\mathrm{ICT}(\mathrm{ms})$ & 0.54 & $<0.0001$ & $<0.0001$ & 0.518 \\
$\mathrm{IRT}(\mathrm{ms})$ & 0.30 & $<0.05$ & $<0.05$ & 0.247 \\
$\mathrm{ET}(\mathrm{ms})$ & -0.08 & $\mathrm{NS}$ & $\mathrm{NA}$ & NA \\
\hline
\end{tabular}

Abbreviations see in Tables 1-3.

\begin{tabular}{|lccccc|}
\hline \multicolumn{2}{|c|}{ Table 5. Comparisons of Clinical Characteristics Among Geometric Patterns } & & \\
& $\begin{array}{c}\text { Normal } \\
(\mathbf{n = 2 2})\end{array}$ & $\begin{array}{c}\text { Concentric } \\
\text { remodeling } \\
(\mathbf{n = 9 )}\end{array}$ & $\begin{array}{c}\text { Eccentric } \\
\text { hypertrophy } \\
(\mathbf{n = 1 2})\end{array}$ & $\begin{array}{c}\text { Concentric } \\
\text { hypertrophy } \\
(\mathbf{n = 1 7})\end{array}$ & P value \\
Age (years) & $48 \pm 13$ & $46 \pm 13$ & $53 \pm 17$ & $54 \pm 15$ & NS \\
Gender (M/F) & $10 / 12$ & $5 / 4$ & $7 / 5$ & $8 / 9$ & NS \\
BMI (kg/m²) & $24 \pm 4$ & $26 \pm 5$ & $23 \pm 3$ & $25 \pm 3$ & NS \\
Heart rate (beats/min) & $71 \pm 10$ & $72 \pm 12$ & $65 \pm 8$ & $65 \pm 10$ & NS \\
Systolic BP (mmHg) & $161 \pm 22$ & $159 \pm 14$ & $165 \pm 17$ & $171 \pm 19$ & NS \\
Diastolic BP (mmHg) & $97 \pm 17$ & $100 \pm 10$ & $98 \pm 14$ & $100 \pm 19$ & NS \\
Dyslipidemia (n, \%) & $7(32 \%)$ & $3(33 \%)$ & $2(17 \%)$ & $6(35 \%)$ & NS \\
Diabetes mellitus $(\mathrm{n}, \%)$ & $7(32 \%)$ & $2(22 \%)$ & $3(25 \%)$ & $6(35 \%)$ & NS \\
\hline
\end{tabular}

Abbreviations see in Tables 1,3.

were obtained from 3 consecutive cardiac cycles and averaged. All echocardiographic measurements were performed by a single experienced cardiologist blinded to all of the other clinical and demographic data.

\section{Statistical Analysis}

The results are expressed as the means \pm SD. The relationship between LVMI and the other continuous study variables was analyzed with simple linear regression analysis. Multiple stepwise linear regression analysis was performed to determine which variables were independent predictors of LVMI. A 1way analysis of variance (ANOVA) with Fisher's PLSD post hoc analysis was used to determine if there were differences among the 4 groups. All statistical analyses were performed with Statview version 5.0 (SAS Institute, Cary, NC, USA). A $\mathrm{P}$-value $<0.05$ was considered significant.

\section{Results}

\section{Patients' Characteristics}

The characteristics of the patients with untreated hypertension are summarized in Table 1 . The population consisted of 60 middle-aged patients with an equal number of males and females; 24 patients $(40 \%)$ were obese, as defined by a BMI $\geq 25 \mathrm{~kg} / \mathrm{m}^{2}$.

\section{Echocardiographic Measurements}

The echocardiography data are summarized in Table 2: 22 patients had a normal LV geometric pattern and 9 had a concentric remodeling pattern; 29 (48\%) had LV hypertrophy, defined as a LVMI was $>115 \mathrm{~g} / \mathrm{m}^{2}$ for men and $>95 \mathrm{~g} / \mathrm{m}^{2}$ for women; 12 patients had eccentric hypertrophy and 17 had concentric hypertrophy.

\section{Association Between LVMI and Other Variables}

The results of a linear regression analysis between LVMI and all of the other variables are shown in Table 3. Systolic BP, LVEF, mitral E/A ratio and LV Tei index were significantly correlated with LVMI (Figure 2). Only LV Tei index was independently correlated with LVMI in the multiple regression analysis (Table 3 ).

\section{Association of LVMI With Components of the Tei Index}

LV Tei index correlated well with LVMI as shown in Table 3 and Figure 2. The Tei index consists of ICT, ET and IRT. Therefore, we examined which components of the Tei index were independently correlated with LVMI (Table 4). Multiple regression analysis showed that both ICT and IRT were independently correlated with LVMI, whereas there was no correlation between ET and LVMI. Furthermore, the correlation between ICT and LVMI was stronger than the correlation between IRT and LVMI ( $\mathrm{P}<0.0001$ vs. $\mathrm{P}<0.05$, respectively).

Differences of LV Dysfunction Among LV Geometric Patterns We analyzed the differences of LV Tei index and its components in the 4 different LV geometric patterns. There were no significant differences in clinical characteristics among geometric patterns (Table 5). LV Tei index and ICT in the group with concentric hypertrophy were significantly greater than in the other 3 groups (Figures $\mathbf{3 A}, \mathbf{B}$ ). The IRT value in the group with concentric hypertrophy was significantly greater than that in the groups with normal geometry and concentric remodeling (Figure 3D). There were no significant differences in ET among the 4 groups (Figure $3 \mathrm{C}$ ).

\section{Discussion}

We examined the correlation between LV mass and LV function by echocardiography in patients with untreated hypertension. The main findings of the present study are: (1) LV Tei index independently correlated with LVMI, and (2) ICT in concentric hypertrophy was significantly greater compared with all other geometric patterns. Our study is the first to demonstrate that LV Tei index correlated with LVMI and LV geometry in patients with untreated hypertension.

Although there are many studies that have examined LV 

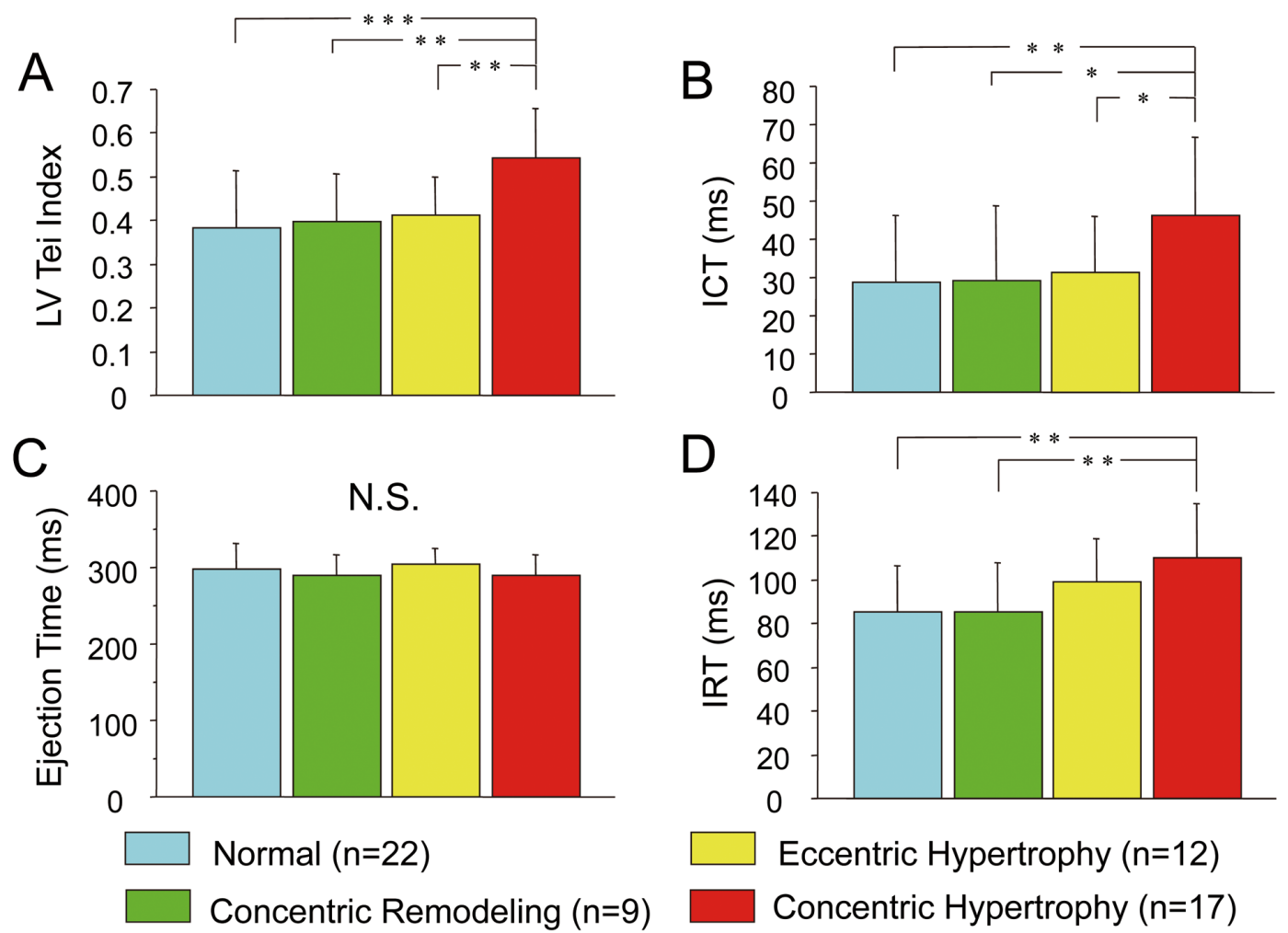

Figure 3. Differences in the left ventricular (LV) Tei index and its components in the 4 LV geometric patterns. ICT, isovolumic contraction time; IRT, isovolumic relaxation time. ${ }^{*} \mathrm{P}<0.05$, ${ }^{\star *} \mathrm{P}<0.01,{ }^{* *} \mathrm{P}<0.001$.

function in patients with hypertension, most of the subjects had already received antihypertensive therapy. Lowering BP may decrease LV mass and modify LV function. Moreover, antihypertensive drugs, such as calcium-channel blockers, $\beta$-blockers, angiotensin-converting enzyme inhibitors, or angiotensin-receptor blockers, should attenuate LV dysfunction. Because none of the subjects in this study had been treated for hypertension, we could eliminate the confounding effects of antihypertensive therapy on the relation between LV function and mass.

\section{Tei Index in Hypertension}

The Tei index has been proposed as a measure of global LV function, combining LV systolic and diastolic functions. ${ }^{12}$ Compared with other conventional parameters of LV function, there is a stronger association between the Tei index and prognosis in various cardiac diseases, which strongly suggests that the Tei index is a more sensitive marker of global LV dysfunction. ${ }^{13-16}$ A modified Tei index, which is calculated using tissue Doppler rather than standard Doppler, has also been proposed. Both the Tei index and the modified Tei index have been used in previous studies to evaluate LV function in hypertensive patients. ${ }^{17-20}$ The modified Tei index was shown to be increased in hypertensive patients before the development of overt hypertrophy, and the increment was more pronounced after the development of hypertrophy. ${ }^{17}$ These results are consistent with the results of our study. Gur et al showed a relationship between the modified Tei index and aortic distensibility in patients with essential hypertension. ${ }^{18} \mathrm{~A}$ large European clinical trial (SILVHIA study) showed that LV Tei index decreased after antihypertensive treatment in hypertensive pa- tients with LV hypertrophy. ${ }^{19}$ However, they did not examine the correlation of Tei index with LVMI or how the various LV geometric patterns influenced the Tei index.

\section{ICT and IRT in Hypertension}

We demonstrated that LVMI significantly correlated with LV Tei index, and also with IRT and ICT, which are 2 components of the Tei index. Importantly, ICT had the strongest correlation with LVMI among the 3 components of the Tei index. This finding suggests that hypertensive LV remodeling has a great effect on intrinsic systolic dysfunction, reflected by a prolonged ICT, even in hypertensive patients with normal LVEF. We should note that a normal EF does not necessarily mean normal systolic function, and ICT is a sensitive parameter for evaluating intrinsic systolic function in patients with essential hypertension. LV systolic dysfunction, expressed by ICT, has been reported to play an important role in the development of diastolic heart failure in patients with hypertension. ${ }^{21}$

\section{Geometric Patterns in Hypertension}

We precisely analyzed LV functional parameters in hypertensive patients after classifying them into 4 different LV geometric patterns. A previous study reported that hypertensive patients with concentric hypertrophy had the highest mortality and cardiovascular event rate, followed by those with eccentric hypertrophy. ${ }^{7}$ These findings are consistent with our finding that LV Tei index and ICT were the highest in concentric hypertrophy. These results suggest that global LV dysfunction, including systolic and diastolic LV dysfunction, is associated with a worse prognosis in patients with concentric hypertrophy. 


\section{Study Limitations}

First, because most of the patients in this study were in the early phase of hypertension with mild LV dysfunction, there were few patients with heart failure. Further research is needed to determine which LV geometric pattern in hypertension is most likely to progresses to heart failure. Second, the study population was small and the study was performed at a single hospital. A multicenter study to confirm these results with a larger number of patients is also required.

\section{Conclusions}

The Tei index provides a better marker for LV dysfunction due to hypertensive hypertrophy than the conventional parameters. LV function was most impaired in patients showing concentric hypertrophy among all the geometric patterns in untreated hypertensive patients.

\section{Disclosures}

None.

\section{References}

1. Levy D, Garrison RJ, Savage DD, Kannel WB, Castelli WP. Prognostic implications of echocardiographically determined left ventricular mass in the Framingham Heart Study. N Engl J Med 1990; 322: $1561-1566$.

2. Kono M, Kisanuki A, Takasaki K, Nakashiki K, Yuasa T, Kuwahara $\mathrm{E}$, et al. Left ventricular systolic function is abnormal in diastolic heart failure: Re-assessment of systolic function using cardiac time interval analysis. $J$ Cardiol 2009; 53: 437-446.

3. Yip G, Wang M, Zhang Y, Fung JW, Ho PY, Sanderson JE. Left ventricular long axis function in diastolic heart failure is reduced in both diastole and systole: Time for a redefinition. Heart 2002; 87: $121-125$.

4. Yu CM, Lin H, Yang H, Kong SL, Zhang Q, Lee SW. Progression of systolic abnormalities in patients with "isolated" diastolic heart failure and diastolic dysfunction. Circulation 2002; 105: 1195-1201.

5. Aizawa Y, Sakata Y, Mano T, Takeda Y, Ohtani T, Tamaki S, et al. Transition from asymptomatic diastolic dysfunction to heart failure with preserved ejection fraction: Roles of systolic function and ventricular distensibility. Circ J 2011; 75: 596-602.

6. Ganau A, Devereux RB, Roman MJ, de Simone G, Pickering TG, Saba PS, et al. Patterns of left ventricular hypertrophy and geometric remodeling in essential hypertension. J Am Coll Cardiol 1992; 19: $1550-1558$.

7. Koren MJ, Devereux RB, Casale PN, Savage DD, Laragh JH. Relation of left ventricular mass and geometry to morbidity and mortality in uncomplicated essential hypertension. Ann Intern Med 1991; 114: $345-352$.

8. Cho KI, Kim SM, Shin MS, Kim EJ, Cho EJ, Seo HS, et al. Impact of gestational hypertension on left ventricular function and geometric pattern. Circ J 2011; 75: S1170-S1176.

9. Tabau JF, Szlachic J, Braun S, Massie BM. Impaired left ventricular function reverse in hypertensive patients with left ventricular hypertrophy. Hypertension 1989; 14: 1-8.

10. Ogihara T, Kikuchi K, Matsuoka H, Fujita T, Higaki J, Horiuchi M, et al; Japanese Society of Hypertension Committee. The Japanese Society of Hypertension Guidelines for the Management of Hypertension (JSH 2009). Hypertens Res 2009; 32: 3-107.

11. Lang RM, Bierig M, Devereux RB, Flachskampf FA, Foster E, Pellikka PA, et al; Chamber Quantification Writing Group. Recommendations for Chamber Quantification: A Report from the American Society of Echocardiography's Guidelines and Standards Committee and the Chamber Quantification Writing Group, Developed in Conjunction with the European Association of Echocardiography, a Branch of the European Society of Cardiology. J Am Soc Echocardiogr 2005; 18: 1440-1463.

12. Tei C. New non-invasive index for combined systolic and diastolic ventricular function. J Cardiol 1995; 26: 135-136.

13. Tei C, Ling LH, Hodge DO, Bailey KR, Oh JK, Rodeheffer RJ, et al. New index of combined systolic and diastolic myocardial performance: A simple and reproducible measure of cardiac function - a study in normal and dilated cardiomyopathy. J Cardiol 1995; 26: 357-366.

14. Tei C, Dujardin KS, Hodge DO, Kyle RA, Tajik AJ, Seward JB. Doppler index combining systolic and diastolic myocardial performance: Clinical value in cardiac amyloidosis. $J$ Am Coll Cardiol 1996; 28: 658-664.

15. Dujardin KS, Tei C, Yeo TC, Hodge DO, Rossi A, Seward JB. Prognostic value of a Doppler index combining systolic and diastolic performance in idiopathic-dilated cardiomyopathy. Am J Cardiol 1998; 82: 1071-1076.

16. Yeo TC, Dujardin KS, Tei C, Mahoney DW, McGoon MD, Seward JB. Value of a Doppler-derived index combining systolic and diastolic time intervals in predicting outcome in primary pulmonary hypertension. Am J Cardiol 1998; 81: 1157-1161.

17. Keser N, Yildiz S, Kurtoğ N, Dindar I. Modified TEI Index: A Promising parameter in essential hypertension? Echocardiography 2005; 22: $296-304$.

18. Gur M, Yilmaz R, Demirbag R, Yildiz A, Ozdogru I, Bas MM, et al. Relationship between myocardial performance index and aortic distensibility in patients with essential hypertension. Int J Clin Pract 2008; 62: 138-142.

19. Liljedahl S, Kahan T, Lind L, Arnlöv J. The effects of antihypertensive treatment on the Doppler-derived myocardial performance index in patients with hypertensive left ventricular hypertrophy: Results from the Swedish irbesartan in left ventricular hypertrophy investigation versus atenolol (SILVHIA). Echocardiography 2009; 26: 753 758.

20. Palmieri V, Okin PM, Bella JN, Wachtell K, Oikarinen L, Gerdts E, et al. Electrocardiographic strain pattern and left ventricular diastolic function in hypertensive patients with left ventricular hypertrophy: The LIFE study. J Hypertens 2006; 24: 2079-2084.

21. Kono M, Kisanuki A, Ueya N, Kubota K, Kuwahara E, Takasaki K, et al. Left ventricular global systolic dysfunction has a significant role in the development of diastolic heart failure in patients with systemic hypertension. Hypertens Res 2010; 33: 1167-1173. 